\title{
Consequences of antepartum hemorrhage and its maternal and perinatal outcome
}

\author{
Himang Jharaik ${ }^{1 *}$, Bishan Dhiman', S. K. Verma ${ }^{1}$, Aditi Sharma²
}

${ }^{1}$ Department of Obstetrics and Gynecology, Kamla Nehru Hospital, Shimla, Himahal Pradesh, India

${ }^{2}$ Department of Dermatology, Dr. Rajendra Prasad Government Medical College, Tanda, Kangra, India

Received: 23 January 2019

Accepted: 05 March 2019

\section{*Correspondence: \\ Dr. Himang Jharaik, \\ E-mail: jharaik7@gmail.com}

Copyright: ( $\subseteq$ the author(s), publisher and licensee Medip Academy. This is an open-access article distributed under the terms of the Creative Commons Attribution Non-Commercial License, which permits unrestricted non-commercial use, distribution, and reproduction in any medium, provided the original work is properly cited.

\begin{abstract}
Background: Antepartum haemorrhage, a life-threatening event, is defined as bleeding per vaginum occurring after the fetus has reached the period of viability, considered to be 20 weeks in developed countries and 28 weeks in countries with low resource settings. We evaluated the consequences of antepartum haemorrhage, their maternal and perinatal outcome so as to outline the proper management of patient in order to improve both maternal and perinatal morbidity and mortality.

Methods: This one-year prospective study totaled 133 cases of APH fulfilling the inclusion criteria were studied. Data was recorded on the MS excel sheet for further analysis and processing.

Results: Total 6693 deliveries were conducted out of which 133 presented as APH and incidence of APH was found out to be $1.98 \%$. Placenta previa was most common. APH was commonly associated with multigravida and most cases were in age group of 26-30 years. Most of the PP and abruption cases were admitted at 34-37 weeks and 31-33 weeks respectively. High risk factors included previous LSCS and D and C, hypertension, multiple pregnancies and malpresentations. Most of the patients underwent preterm LSCS. Most fetal complications were due to prematurity. $58.6 \%$ patients were transfused blood. Overall perinatal mortality was $20.1 \%$ and maternal mortality was zero.

Conclusions: Early diagnoses, timely referrals and transfusion facilities along with trained team of doctors with wellequipped ICU facility goes a long way in avoiding APH related maternak and fetal complications.
\end{abstract}

Keywords: Abruptio placenta, Antepartum hemorrhage, Placenta previa

\section{INTRODUCTION}

Haemorrhage is a life-threatening event and hence obstetrics has aptly been honoured as the business of blood. Haemorrhage forms a big chunk amongst the causes of maternal mortality and is in fact one of the gravest obstetrics emergencies whether antepartum or postpartum. Antepartum haemorrhage is defined as bleeding per vaginum occurring after the fetus has reached the period of viability but before the birth of baby. This implies bleeding from genital tract after 20 weeks of gestation until delivery in developed countries and 28 weeks in countries with low resource settings, lacking adequate neonatal facilities., ${ }^{1,2}$ Two to five percent of all pregnancies are complicated by antepartum haemorrhage. Royal college of obstetricians and gynaecologists (RCOG) defines blood loss by a combination of volume and signs of clinical shock to guide management. ${ }^{3}$

For the purpose of these guidelines, the following definitions have been used: Spotting- staining, streaking 
or blood spotting noted on under garments or sanitary protection. Minor haemorrhage- blood loss less than 50 $\mathrm{ml}$ that has settled. Major haemorrhage - blood loss of 50-1000 ml, with no signs of clinical shock. Massive haemorrhage-blood loss greater than $1000 \mathrm{ml}$ with signs of clinical shock.

Antepartum haemorrhage can be due to placenta previa, abruptio placentae or extra placental causes, where first two accounts for more than half of the causes of APH.

Placenta previa refers to the condition when the placenta is situated wholly or partially in the lower uterine segment and accounts for one third of all cases of APH. It is further classified as type I - if implantation is in lower segment but does not reach the internal os, Type IIplacenta reaches the internal os but does not cover it, Type III- placenta covers the internal os but not at full dilatation, Type IV- placenta covers internal os even at full dilatation of cervix.

The second most common cause of APH is placental abruption which is defined as separation of the placenta either partially or totally from its implantation site before delivery.

Extra placental causes may include cervical polyps, cervical erosions, endocervical erosions, cancer of cervix, cervicitis, varicosities (vaginal, vulvar and cervical) vaginal infections, foreign bodies, genital lacerations, bloody show, degenerating uterine myomata, vasa previa and marginal placental separation. It may even be of undetermined origin. ${ }^{4}$ Maternal complications of APH are malpresentations, premature labour, postpartum haemorrhage, sepsis, shock and retained placenta. They also include higher rates of caesarean section, peripartum hysterectomy, coagulation failure, puerperal infections and even death. Maternal morbidity and mortality are attributed to the sequence of haemorrhage, hypofibrinogenemia, renal failure and puerperal infection. Pulmonary edema, caesarean section, postpartum anemia and Sheehan's syndrome are other major maternal morbidities. ${ }^{5}$

Fetal complications are premature delivery, low birth weight, intrauterine death, congenital malformations and birth asphyxia. The latter is due to placental separation or hypotension in mother as a result of haemorrhage. Antepartum haemorrhage may frequently result in low birth weight babies. This can be an effect of preterm labour or repeated small events of haemorrhage causing chronic placental insufficiency and fetal growth retardation. The overall perinatal mortality increases to between $4-8 \%{ }^{6}$

Authors therefore proposed to conduct a prospective study, to evaluate the consequences of antepartum haemorrhage, their maternal and perinatal outcome, so as to outline the important causes and proper management of patient in order to improve both maternal and perinatal morbidity and mortality and specify as to what areas required improvement in a developing country like India to improve the same.

Data collected from this prospective study will be used to gauge the severity of this problem so that management and preventive protocol could be established to avert possible fatal maternal and perinatal outcome.

\section{METHODS}

This prospective study was conducted in the Department of Obstetrics and Gynaecology, Kamla Nehru State Hospital for Mother and Child, Indira Gandhi Medical College, Shimla, H.P from July 1, 2016 to June 30, 2017 and 133 cases of APH were studied.

\section{Exclusion criteria}

- All cases of antepartum hemorrhage $\geq 28$ weeks of gestation were included in this study. Cases with APH below 28weeks of gestation and patients suffering from any other bleeding disorders were excluded.

The cases of antepartum haemorrhage with clinical findings and ultrasound reports confirming placenta previa, abruptio placenta or APH due to any other cause were admitted in the hospital. The data collected included maternal age, parity, gestational age, presentation, booking status, education, occupation, residential address and severity of haemorrhage.

The diagnosis of all cases was made on the basis of history, clinical evaluation which included general physical examination, per abdomen, per speculum, per vaginal exam and USG. Line of management i.e. conservative or emergency lower segment caesarean section was planned according to the clinical condition of the patient and fetus. All facilities of neonatal intensive care unit (NICU) to deal with preterm and sick infants were available in pediatric unit of this institution.

\section{Statistical analysis}

Data collected was transformed into MS excel sheet for further processing and analysis.

\section{RESULTS}

Out of total 6693 deliveries a total 150 patients were admitted with APH. 133 patients fulfilled the inclusion criteria. The incidence of APH in our institute is $1.98 \%$.

Among 133 deliveries there were 4 twins and 1 triplet, so the total number of babies delivered were 139. The comparison between causes of APH and its consequences was studied. Out of total cases, $58.65 \%$ were placenta previa, $23.31 \%$ abruptio placentae and $18.05 \%$ undetermined (Table1). 
Table 1: Distribution of causes of APH.

\begin{tabular}{|l|l|}
\hline $\begin{array}{l}\text { Total no. of deliveries } \\
\text { No. of APH cases }\end{array}$ & 6693 \\
\hline Types of APH & 133 \\
\hline Abruptio placentae & (31) $23.31 \%$ \\
\hline Placenta previa & (78) $58.65 \%$ \\
\hline Undetermined & (24) $18.05 \%$ \\
\hline
\end{tabular}

Maximum number of patients (40\%) were in age group 26-30 years. In this study $71.43 \%$ patients were multigravida and $28.57 \%$ primigravida.

Placenta previa was commonly associated with multigravidas whereas abruption was commonly seen in primigravidae. Mean gavidity was $2.24 \pm 1.17$. Booking rate was $82 \%$. Most cases of APH with placenta previa were seen in lower class and upper lower class of Modified Kuppuswamy classification. Abruption was also commonly associated with lower and lower middle class (Table 2).

A $77 \%$ of APH cases had mild bleeding at presentation out of which $58 \%$ were placenta previa. Severe bleeding was observed in $7 \%$ cases and $67 \%$ of which were due to abruption placentae. A $42 \%$ cases of placenta previa were admitted at 34-37 weeks of gestation and abruptio placenta at 31-33 weeks gestation. $60 \%$ of the APH delivered between 34-37 weeks of gestation whereas $39.8 \%$ cases delivered at gestation $>37$ weeks (Table 3 ).
A $76 \%$ patients with previous LSCS and 64\% with history of dilatation and curettage had placenta previa. Hypertension was noted in $16 \%$ of the patients with APH. Out of these $68.8 \%$ patients had abruption. Multiparity, malpresentations, polyhydramnios and hypothyroidism were also studied as associated risk factors (Table 4).

A $64 \%$ of the patients underwent LSCS out of which $66 \%$ were placenta previa.

$36 \%$ of the patients had vaginal delivery out of which $46 \%$ were placenta previa (Type 1). A $59 \%$ of the patients had preterm deliveries out of which $73 \%$ were LSCS and $41 \%$ of the term deliveries had $50 \%$ LSCS rate. PPH was seen in $41 \%$ of the patients. Out of total $58.6 \%$ of the patients needed blood transfusion. Mean $1.09 \pm 1.32$ (Table 5).

Anemia was seen in $32 \%$ of the patients, anemia with shock in $4.5 \%$. While in one patient shock was followed by myocardial infarction. One patient went into shock and DIC. No maternal death was observed. A $25.8 \%$ neonates had preterm deliveries, out of which $72 \%$ were placenta previa. $12.2 \%$ cases were associated with asphyxia out of which $59 \%$ were placenta previa (Table 6). Majority of neonates weighed between 2.1-2.5 Kgs. Low birth weight was due to prematurity. Mean $2.17 \pm 0.36$ abruptio placenta had significant relationship with low APGAR score. $75 \%$ of NICU admissions were due to fetal distress out of which $48 \%$ cases were of placenta previa and $36 \%$ abruptio placenta (Table 7).

Table 2: Distribution of causes of APH with age, gravidity and booking status.

\begin{tabular}{|c|c|c|c|c|}
\hline & Age distribution (years) & Abruptio placentae & Placenta previa & Undetermined \\
\hline \multicolumn{5}{|l|}{ Age (years) } \\
\hline$<20$ & $4(25 \%)$ & $1(25.0 \%)$ & $3(75.0 \%)$ & $0(0.0 \%)$ \\
\hline $20-25$ & $52(29 \%)$ & $15(29.0 \%)$ & $21(40.0 \%)$ & $16(31.0 \%)$ \\
\hline $26-30$ & $53(13 \%)$ & $7(13.0 \%)$ & $39(74.0 \%)$ & $7(13.0 \%)$ \\
\hline $31-35$ & $16(44 \%)$ & $7(44.0 \%)$ & $9(56.0 \%)$ & $0(0.00 \%)$ \\
\hline$>35$ & $8(13)$ & $1(13.0 \%)$ & $6(75.0 \%)$ & $1(13.0 \%)$ \\
\hline \multicolumn{5}{|l|}{ Gravidity } \\
\hline 1 & $38(28.5 \%)$ & $17(44.7 \%)$ & $15(39.47 \%)$ & $6(15.7 \%)$ \\
\hline 2 & $53(39.8)$ & $7(13.2 \%)$ & $33(62.2 \%)$ & $13(25.5 \%)$ \\
\hline 3 & $24(18.0)$ & $5(9.4 \%)$ & $17(70.8 \%)$ & $2(8.33 \%)$ \\
\hline$\geq 4$ & $18(13.5)$ & $2(11.1 \%)$ & $13(72.22 \%)$ & $3(16.66 \%)$ \\
\hline \multicolumn{5}{|c|}{ Booking status } \\
\hline Booked & (109) $82 \%$ & $26(23.85 \%)$ & $65(59.63 \%)$ & $18(16.51 \%)$ \\
\hline Unbooked & (24) $18 \%$ & $5(20.83 \%)$ & $13(54.17 \%)$ & $6(25.00 \%)$ \\
\hline
\end{tabular}

Table 3: Distribution of gestational age with cause of APH.

\begin{tabular}{|l|l|l|l|l|l|}
\hline Gest age at admission & No. of cases & $28-30$ weeks & $31-33 w e e k s$ & $34-37$ weeks & $>37$ weeks \\
\hline Abruptio placentae & $(31) 23.31 \%$ & $6(19 \%)$ & $11(35 \%)$ & $9(29 \%)$ & $5(16 \%)$ \\
\hline Placenta previa & $(78) 58.65 \%$ & $11(14 \%)$ & $26(33 \%)$ & $33(42 \%)$ & $8(10 \%)$ \\
\hline Undetermined & $(24) 18.05 \%$ & $9(38 \%)$ & $4(17 \%)$ & $9(38 \%)$ & $2(8 \%)$ \\
\hline Gest age at delivery & & & & & \\
\hline Preterm & $(80) 60.1 \%$ & $14(17.5 \%)$ & $18(22.5 \%)$ & $48(60 \%)$ & $0(0.0 \%)$ \\
\hline Term & $(53) 39.8 \%$ & $0(0.0 \%)$ & $0(0.0 \%)$ & $22(41.5 \%)$ & $31(58.4 \%)$ \\
\hline
\end{tabular}


Table 4: Distribution of causes of APH with obstetric history and associated risk factors.

\begin{tabular}{|c|c|c|c|c|}
\hline & No. of patients & Abruptio placentae & Placenta previa & Undetermined \\
\hline \multicolumn{5}{|l|}{ Previous history } \\
\hline Abortion & $25(9 \%)$ & $4(16.00 \%)$ & $15(60.00 \%)$ & $6(24.00 \%)$ \\
\hline Abortion and D and C & $14(11 \%)$ & $1(7.14 \%)$ & $9(64.29 \%)$ & $4(28.57 \%)$ \\
\hline LSCS & $13(10 \%)$ & $3(23.08 \%)$ & $10(76.92 \%)$ & $0(0.00 \%)$ \\
\hline Abortion, LSCS and D and C & $2(2 \%)$ & $1(50.00 \%)$ & $1(50.00 \%)$ & $0(0.00 \%)$ \\
\hline \multicolumn{5}{|c|}{ Risk factors } \\
\hline Hypertension & $22(16 \%)$ & $15(68.8 \%)$ & $6(27.27 \%)$ & $1(4.55 \%)$ \\
\hline Multiparity & $7(5.26 \%)$ & $1(14.29 \%)$ & $6(85.7 \%)$ & $0(0.00 \%)$ \\
\hline Twins & $4(3 \%)$ & $3(75 \%)$ & $1(25 \%)$ & $0(0.00 \%)$ \\
\hline Malpresentations & $7(5.26 \%)$ & $0(0.00 \%)$ & $5(71.4 \%)$ & $2(28.7 \%)$ \\
\hline IUGR & $7(5.26 \%)$ & $2(28.57 \%)$ & $2(28.57 \%)$ & $3(42.86 \%)$ \\
\hline Polyhydramnios & $6(4.5 \%)$ & $4(66 \%)$ & $0(0.00 \%)$ & $2(33.33 \%)$ \\
\hline Hypothyroidism & $6(4.5 \% 0$ & $3(50 \%)$ & $2(33.33 \%)$ & $1(16.6 \%)$ \\
\hline Elderly & $4(3.01 \%)$ & $0(0.00 \%)$ & $3(75 \%)$ & $1(25 \%)$ \\
\hline Triplet & $1(.75 \%)$ & $1(100 \%)$ & $0(0.00 \%)$ & $0(0.00 \%)$ \\
\hline
\end{tabular}

Out of the total 139 deliveries, 123 were live neonates, 12 expired in NICU. 12 were intrauterine deaths and 4 were still births. Neonatal deaths in toto were 28 i.e. $20.1 \%$.
Overall deaths of neonates illustrate the most common cause is neonatal shock seen in $46 \%$ followed by sepsis and shock seen in $32 \%$ neonates (Table 8 ).

Table 5: Distribution of causes of APH with mode of delivery and PPH as a complication.

\begin{tabular}{|l|l|l|l|l|}
\hline Mode of delivery & No. of patients & Abruption & Placenta previa & Undetermined \\
\hline LSCS & $85(63.9 \%)$ preterm-58 term- 27 & $22(26 \%)$ & $56(66 \%)$ & $7(8 \%)$ \\
\hline Vaginal delivery & $48(36 \%)$ preterm-21 term -27 & $9(19 \%)$ & $22(46 \%)$ & $17(35 \%)$ \\
\hline PPH & & & & \\
\hline Present & $55(41 \%)$ & $15(27 \%)$ & $36(65 \%)$ & $4(7 \%)$ \\
\hline
\end{tabular}

Table 6: Distribution of causes of APH with maternal fetal complications.

\begin{tabular}{|c|c|c|c|c|}
\hline & No. of cases & Abruptio placentae & Placenta previa & Undetermined \\
\hline \multicolumn{5}{|l|}{ Fetal complications } \\
\hline Preterm & $36(25.8 \%)$ & $7(19 \%)$ & $26(72 \%)$ & $3(8 \%)$ \\
\hline Asphyxia & $17(12.2 \%)$ & $4(24 \%)$ & $10(59 \%)$ & $3(18 \%)$ \\
\hline IUD & $12(8.6 \%)$ & $5(42 \%)$ & $6(50 \%)$ & $1(8 \%)$ \\
\hline Jaundice & $10(15.8 \%)$ & $4(40 \%)$ & $4(40 \%)$ & $2(20 \%)$ \\
\hline Distress & $4(2.8 \%)$ & $2(50 \%)$ & $1(25 \%)$ & $1(25 \%)$ \\
\hline Still birth & $4(2.8 \%)$ & $4(100 \%)$ & $0(0 \%)$ & $0(0 \%)$ \\
\hline Fever & $3(2.15 \%)$ & $2(67 \%)$ & $1(33 \%)$ & $0(0 \%)$ \\
\hline Hypoglycemia & $1(0.7 \%)$ & $0(0 \%)$ & $1(100 \%)$ & $0(0 \%)$ \\
\hline \multicolumn{5}{|l|}{ Maternal complications } \\
\hline Anemia & (43) $32.33 \%$ & $14(32.56 \%)$ & $24(55.81 \%)$ & $5(11.63 \%)$ \\
\hline Anemia, Shock & (6) $4.51 \%$ & $2(33.33 \%)$ & $2(33.33 \%)$ & $2(33.33 \%)$ \\
\hline HELLP & (2) $1.50 \%$ & $1(50.00 \%)$ & $1(50.00 \%)$ & $(0.00 \%)$ \\
\hline Anemia, Pyrexia & (5) $3.76 \%$ & $0(0.00 \%)$ & $4(80.00 \%)$ & $1(20.00 \%)$ \\
\hline $\begin{array}{l}\text { Shock, myocardial infarction, } \\
\text { Anemia }\end{array}$ & (1) $0.75 \%$ & $1(100.00 \%)$ & $0(0.00 \%)$ & $0(0.00 \%)$ \\
\hline Shock, DIC, pyrexia & (1) $0.75 \%$ & $1(100.00 \%)$ & $0(0.00 \%)$ & $0(0.00 \%)$ \\
\hline Maternal death & 0 & 0 & 0 & 0 \\
\hline
\end{tabular}


Table 7: Distribution of causes of APH with birth weight and APGAR score.

\begin{tabular}{|l|l|l|l|l|}
\hline Birth weight & No. of cases & Abruptio placentae & Placenta previa & Undetermined \\
\hline$<1$ & $2(1 \%)$ & $1(50 \%)$ & $1(50 \%)$ & $0(0 \%)$ \\
\hline $1-1.5$ & $25(18 \%)$ & $8(32 \%)$ & $12(48 \%)$ & $5(20 \%)$ \\
\hline $1.6-2$ & $30(22 \%)$ & $7(23 \%)$ & $21(70 \%)$ & $2(7 \%)$ \\
\hline $2.1-2.5$ & $40(29 \%)$ & $7(18 \%)$ & $25(63 \%)$ & $8(20 \%)$ \\
\hline $2.6-3$ & $40(29 \%)$ & $8(20 \%)$ & $22(55 \%)$ & $10(25 \%)$ \\
\hline$>3$ & $2(1 \%)$ & $2(100 \%)$ & $0(0 \%)$ & $0(0 \%)$ \\
\hline Apgar & & & & \\
\hline $0-3$ & $16(12 \%)$ & $9(56 \%)$ & $6(38 \%)$ & $1(6 \%)$ \\
\hline $4-7$ & $31(22 \%)$ & $10(32 \%)$ & $16(52 \%)$ & $5(16 \%)$ \\
\hline$>7$ & $92(66 \%)$ & $14(15 \%)$ & $59(64 \%)$ & $19(20 \%)$ \\
\hline
\end{tabular}

Table 8: Distribution of causes of APH with fetal outcome.

\begin{tabular}{|l|l|l|l|l|}
\hline Out come & Total & Abruption & Placenta previa & Undetermined \\
\hline Live & $123(88.4 \%)$ & $24(19.5 \%)$ & $76(61.7 \%)$ & $23(18.6 \%)$ \\
\hline IUD & $12(8.6 \%)$ & $5(41.6 \%)$ & $6(50 \%)$ & $1(8.33 \%)$ \\
\hline Still birth & $4(2.8 \%)$ & $4(100 \%)$ & $0(0.00 \%)$ & $0(0.00 \%)$ \\
\hline Expired in NICU & $12(8.6 \%)$ & $2(16.6 \%)$ & $7(58.3 \%)$ & $3(25 \%)$ \\
\hline Cause of death & \multicolumn{3}{|l}{} & \\
\hline Hypoglycemia, seizures & $1(4 \%)$ & $0(0.00 \%)$ & $0(0.00 \%)$ & $1(100 \%)$ \\
\hline RDS & $2(7 \%)$ & $1(50 \%)$ & $1(50 \%)$ & $0(0.00 \%)$ \\
\hline Sepsis, shock & $9(32 \%)$ & $3(33.33 \%)$ & $4(44.44 \%)$ & $2(22.22 \%)$ \\
\hline Shock & $13(46 \%)$ & $7(53.8 \%)$ & $5(38.4 \%)$ & $1(0.00 \%)$ \\
\hline Shock, pulmonary hemorrhage & $3(11 \%)$ & $0(0.00 \%)$ & $3(100 \%)$ & $0(0.00 \%)$ \\
\hline Total & $28(100 \%)$ & $11(39 \%)$ & $13(46.4 \%)$ & $4(14.2 \%)$ \\
\hline & & & & \\
\hline
\end{tabular}

\section{DISCUSSION}

Incidence of APH in present study was $1.98 \%$. This was in accordance with the findings of Kedar $\mathrm{K}$ et al, Bhandiwad A et al, Bhide A et al and Arora A et al. ${ }^{7-10}$

In present study $82 \%$ patients of APH were booked and $18 \%$ were unbooked. Tyagi $\mathrm{P}$ et al and Bhandiwad A et al, reported higher incidences of unbooked cases in their studies. ${ }^{8,11}$ The inconsistency noted maybe because of the free facilities provided by the state government giving an easy access for antenatal checkup.

Placenta previa was the main cause of APH i.e. 58.5\%. Abruptio placentae and undetermined cases were $23.3 \%$ and $18.05 \%$ respectively. Our results were consistent with the studies conducted by Adekanle DA et al and Jejani A et al. ${ }^{12,13}$ Mean age of women presenting with APH in present study was $26.7 \pm 4.5$ years with $40 \%$ in age group of 26-30 years and 39\% between 20-25 years age. This is also consistent with studies conducted by Tyagi $\mathrm{P}$ et al and Adekanle DA et al, in which $61 \%$ and $40 \%$ cases of APH were observed between 26-30 years of age respectively. ${ }^{11,12}$

In present study $75.1 \%$ of the women with APH were multigravidae and $24.8 \%$ were primigravidae. Mean parity was $2.24 \pm 1.17$. This was consistent with the studies conducted by Samal SK et al and Singhal et al, in which placenta previa was more common than abruption. ${ }^{14,15}$ Association of abruption was commonly seen with primigravida and placenta previa was commonly seen with multigravida.

The mean gestational age at delivery in present study was $35.22 \pm 2.82$ weeks and $60.1 \%$ of the patients in present study had preterm deliveries which was almost similar to studies conducted by Samal SK et al and Singhal S et al. ${ }^{14,15}$ This higher rate of preterm deliveries could be due to early decisions and surgical intervention in view of maternal health.

Hypertension was seen in $16 \%$ APH cases, out of which $68.8 \%$ cases had abruption. This was consistent with the studies conducted by Sarwar I et al and Bhandiwad A et al. ${ }^{8,16}$ In present study $19 \%$ APH cases had abortions, $22 \%$ abortions and $12 \%$ patients had previous LSCS which was consistent with the study conducted by Samal SK et al, Sekiguchi A et al, also reported similar a incidence. $^{14,17}$

Malpresentations were seen in 5.2\% cases which was consistent with the findings of Samal SK et al, Jejani A et al, and Sheikh F et al. ${ }^{13,14,18}$

In present study $63 \%$ patients underwent caesarean section, while $46 \%$ patients delivered vaginally. This was 
found consistent with the studies conducted by Chufamo $\mathrm{N}$ et al, Sheikh F et al, Adekanle DA et al, Samal SK et al and Arora R et al. ${ }^{10,12,15,18,19}$ This higher incidence of caesarean section was due to maternal indications which included hemorrhagic shock, major placenta previa and fetal indications like malpresentations, twins' gestations and acute fetal distress.

Various complications observed included $\mathrm{PPH} 41 \%$, anemia $32.3 \%$, shock $6 \%$ and DIC in 1 patient $(.75 \%)$. Our findings were consistent with Kalam F et al. ${ }^{20}$ with incidences of anemia at $38 \%$, PPH $38 \%$, shock $22 \%$ and DIC $2 \%$. Almost similar incidences were found in studies conducted by Sharmila G et al. ${ }^{21}$

In present study $58.6 \%$ had blood transfusion. $43 \%$ of the patients were transfused 1-2 units of blood which was similar as illustrated by Tyagi $\mathrm{P}$ et al and Chufamo $\mathrm{N}$ et al. ${ }^{11,19}$

Prematurity was the most common cause of LBW which was seen in $70 \%$ of the neonates weighing $<2.5 \mathrm{kgs} .30 \%$ of neonates had birth weight $>2.5 \mathrm{kgs}$. Mean birth weight was $2.17 \pm 0.36 \mathrm{kgs}$. Our findings were consistent with Samal SK et al,14, Sharmila G et al and Sekiguchi A et al. ${ }^{17} 14,21$

In present study $66 \%$ neonates had APGAR score above 7 at 5 mins of birth while $34 \%$ had scores less than 7 . Our results were consistent with the findings of Adeknale DA et al, Rajini P et al, Samal SK et al, with $74.6 \%, 80.4 \%$ incidences of APGAR score $>7$ at 5 mins. ${ }^{12,15,22}$

In present study the most common fetal complications observed were prematurity $25.8 \%$, fetal distress $30 \%$, asphyxia $12.2 \%$, jaundice $7.1 \%$, sepsis $2.1 \%$ still birth $2.8 \%$, IUD $2.8 \%$, early neonatal death $5.7 \%$. This is consistent with the studies conducted by Singhal SR, et al, Samal SK et al, Taylor F et al, and Bhandiwad A et al. ${ }^{8,14,23,24}$

Perinatal mortality was observed in $20.1 \%$ of cases of APH in present study. Most common causes were prematurity related complications. Neonatal death rate was $8.6 \%, 11.5 \%$ cases were of IUD and these were most commonly seen with abruption followed by placenta previa. Results were similar to studies conducted by Singhal $\mathrm{S}$ et al and Maurya A et al, Chufamo $\mathrm{N}$ et al, calculated the perinatal mortality to be $36.9 \%$ while Arora R et al. ${ }^{10,15,19,25}$ reported very high mortality rate of $61.5 \%$. The lower neonatal death in present study may be due better neonatal care facilities with well-equipped NICU at our institute. In present study no maternal deaths were observed. This was consistent with the study of Samal SK et al.15 Higher rate of booked cases, proper antenatal check-ups, better referral services, super speciality services, well equipped ICU and $24 \times 7$ blood bank facility may be the reason for zero maternal mortality in present study.

\section{CONCLUSION}

Antepartum haemorrhage is a leading cause of maternal morbidity and mortality. Placenta previa and abruptio placentae are the commonest type of APH with hypertension and multiparity being the major risk factors for APH. Anemia and PPH are the most common complications. Antenatal patients with APH must be considered a high-risk pregnancy.

Timely treatment initiated by a trained team of doctors and well-equipped ICU facility to deal with these cases goes a long way in avoiding maternal and fetal morbidity.

Early diagnoses, timely referrals and transfusion facilities can also aid in decreasing maternal morbidity and mortality. Above all awareness of antenatal care during pregnancy, knowledge of various government schemes for antenatal patients, importance of institutional deliveries and adoption of various contraceptive methods (temporary as well as permanent) are the key factors to avoid various complications due to APH.

Funding: No funding sources

Conflict of interest: None declared

Ethical approval: The study was approved by the Institutional Ethics Committee

\section{REFERENCES}

1. Amitava RS, Saikat SR, Biswajit N, Gourab M, Jayanta M. Management of obstetric haemorrhage. Med J Anaes. 2010;20(4): 499-508.

2. Adelja LM, Taiwo OO. Maternal and fetal outcome of obstetric emergencies in a tertiary health institution in South-Western Nigeria. ISRN Obstet Gynecol.2011:1-4.

3. RCOG. Antepertum haemorrhage clinical Green top guidelines no 63. The Royal college of Obstetricians and Gynaecologists. 2011

4. Arias F, Daftary SN, Bhine GA. Bleeding during pregnancy. In: Practical guide to high risk pregnancy and delivery, $3^{\text {rd }}$ ed. New Delhi: Elsevier, 2008. Chapter 13:323-57.

5. Sheiner E, Shoham-Vardi I, Hadar A, Hallak M, Hackmon R, Mazor M. Incidence, obstetrics risk factors and pregnancy outcome of preterm placental abruption: A retrospective analysis. J Matern Fetal Neonatal Med. 2002;11(1):34-39

6. Mabic WC. Placenta previa. Clin Perinatol. 1992;19(2):425-35.

7. Kedar K, Uikey P, Pawar A, Choudhary A. Maternal and fetal outcome in antepartum haemorrhage: a study at tertiary care hospital. Int $\mathbf{J}$ Reprod Contracept Obstet Gynecol. 2016;5:1386-93.

8. Bhandiwad A, Bhandiwad AA. A Study of maternal and fetal outcomes in antepartum haemorrhage. J Evid based Med Healthcare. 2014;1(6):406-27. 
9. Bhide A, Thilaganathan B. Recent advances in the management of placenta previa. Curr Opin Gynecol. 2004;16 (6):447-51.

10. Arora R. Devi U, Majumder. Perinatal morbidity and mortality in antepartum haemorrhage. J Obstet Gynecol India. 2001;51(3):102-04.

11. Tyagi P, Yadav N, Sinha P, Gupta U. Study of antepartum haemorrhage and its maternal and perinatal outcome. Int J Reprod Contracept Obstet Gyneco.1 2016;5:3972-77.

12. Adekanle DA, Adeyemu A, Fadero F. Antepartum haemorrhage and pregnancy outcome. J Med and Med Sci. 2011;2(12):1243-47

13. Jejani A, Kawthalkar A. Study of obstetric outcome in antepartum haemorrhage. Panacea $\mathrm{J}$ Med Sci 2015;5(3):153-57.

14. Singhal S, Nymphaea NS, Nanda S. Maternal and perinatal outcome in antepartum haemorrhage: A study at a tertiary care referral institute. Inter $\mathbf{J}$ Gynecol Obstet. 2008;9(2):5580.

15. Samal SK, Rathod S, Rani R, Ghose S. Maternal and perinatal outcomes in cases of antepartum haemorrhage: a 3-year observational study in a tertiary care hospital. Int J Reprod Contracept Obstet Gynecol. 2017;6:1025-29.

16. Sarwar I, Abbasi AN, Islam A. Abruptio placenta and its complications at Ayub teaching hospital Abbottabad. J Ayub Med Coll Abbottabad. 2006;18(1):27-31.

17. Sekiguchi A, Nakai A, Kawabata I, Hayashi M, Takeshita T. Type and Location of placenta previa affect preterm delivery risk related to antepartum hemorrhage. Int J Med Sci. 2013;10(12):1683-88.

18. Sheikh F, Khokhar SA, Sirichan P, Shaikh RB. A study of antepartum haemorrhage: maternal and perinatal outcomes. Med channel Gynaecol Obstet. 2010;16(2):268-71.

19. Chufamo N, Segni H, Alemayehu YK. Incidence, contributing factors and outcomes of antepartum hemorrhage. Uni J Pub Health. 2015;3(4):153-59.

20. Kalam F, Faruq MO, Chowdhary SB. Maternal and perinatal mortality, morbidity and risk factor evalution in ante partum hemorrhage associated with Placenta Previa, Bangladesh. Crit Care J 2013;12:6570.

21. Singhal S, Nymphaea NS, Nanda S. Maternal and perinatal outcome in antepartum haemorrhage: A study at a tertiary care referral institute. Inter $\mathbf{J}$ Gynecol Obstet. 2008;9(2):5580.

22. Rajini P, Devi A, Singh A, Grishma P. Maternal and Perinatal Outcome in Cases of Antepartum Hemorrhage in Gandhi Hospital. J Dental Med Sci. 2016;15(6):09-11.

23. Singhal SR, Chaudhary S, Nanda S, Dahiya P. Characteristics of patients of ante-partum hemorrhage at a tertiary care centre. Indian J Obstetr Gynecol Res. 2016;3(2):86-89.

24. Taylor F. Clinical presentation and risk factors of placental abruption. Acta Obstet Gynecol Scand. 2006;85(6):700-05.

25. Maurya A, Arya S. Study of antepartum haemorrhage and its maternal and perinatal outcome. Int J Sci Res Pub. 2014;4(2):2250-3153.

Cite this article as: Jharaik H, Dhiman B, Verma SK, Sharma A. Consequences of antepartum hemorrhage and its maternal and perinatal outcome. Int J Reprod Contracept Obstet Gynecol 2019;8:1480-6. 